University of Wollongong

Research Online

Faculty of Law, Humanities and the Arts Papers (Archive)

$1-1-2018$

Chasing the thrill or just passing the time? Trialing a new mixed methods approach to understanding heterogeneity amongst recreational fishers based on motivations

Christopher A. Magee

University of Wollongong, cmagee@uow.edu.au

Michelle A. Voyer

University of Wollongong, mvoyer@uow.edu.au

Alistair Mcllgorm

University of Wollongong, amcilgor@uow.edu.au

Owen H. Li

University of Wollongong, owenl@uow.edu.au

Follow this and additional works at: https://ro.uow.edu.au/lhapapers

Part of the Arts and Humanities Commons, and the Law Commons

Research Online is the open access institutional repository for the University of Wollongong. For further information contact the UOW Library: research-pubs@uow.edu.au 


\title{
Chasing the thrill or just passing the time? Trialing a new mixed methods approach to understanding heterogeneity amongst recreational fishers based on motivations
}

\begin{abstract}
Human dimensions researchers and fisheries managers have long recognized the value of exploring the heterogeneity that exists amongst recreational fishers. Understanding the differences between fishers has the potential to assist managers in developing targeted communication strategies, direct resources to active management more efficiently and improve understanding of how fishers will respond to changes in regulations or new management interventions. Human dimensions research has traditionally explored fisher heterogeneity through research into the different reasons why people choose to fish, as well as attempts to categorize or segment fishers using variable based approaches. These studies have, to date, relied primarily on large scale, quantitative survey techniques with a particular focus on fisher avidity and commitment. They are therefore limited in their ability to explain how different fishing motivations might interact within an individual, why particular motivations are prioritized, and how this might influence fisher behavior and attitudes. This study trialed a mixed methods approach to understanding fisher heterogeneity based primarily on motivations using a case study in NSW, Australia. This trial involved utilizing a person-centered approach known as Latent Class Analysis (LCA), followed by qualitative, in depth focus group discussions. This revealed five distinct fisher classes; Social fishers, Trophy Fishers, Outdoor Enthusiasts, Generalists and Hunter-Gatherers, each with distinct and significantly different combinations of catch and non-catch-related motivations. The qualitative analysis sought to explore the intersection of motivations and attitudes towards management within and across the different fisher classes. The results highlighted the importance of more detailed examination of the intersection between motivations and attitudes in future LCA, with a particular focus on the potential influence of mastery (or challenge/experience) motivations on fisher attitudes to wards marine and fisheries management approaches.
\end{abstract}

Disciplines

Arts and Humanities | Law

\section{Publication Details}

Magee, C., Voyer, M., Mcllgorm, A. \& Li, O. (2018). Chasing the thrill or just passing the time? Trialing a new mixed methods approach to understanding heterogeneity amongst recreational fishers based on motivations. Fisheries Research, 199 107-118.

This journal article is available at Research Online: https://ro.uow.edu.au/lhapapers/3354 
Chasing the thrill or just passing the time? Trialing a new mixed methods approach to understanding heterogeneity amongst recreational fishers based on motivations.

\section{Abstract}

Human dimensions researchers and fisheries managers have long recognized the value of exploring the heterogeneity that exists amongst recreational fishers. Understanding the differences between fishers has the potential to assist managers in developing targeted communication strategies, direct resources to active management more efficiently and improve understanding of how fishers will respond to changes in regulations or new management interventions. Human dimensions research has traditionally explored fisher heterogeneity through research into the different reasons why people choose to fish, as well as attempts to categorize or segment fishers using variable based approaches. These studies have, to date, relied primarily on large scale, quantitative survey techniques with a particular focus on fisher avidity and commitment. They are therefore limited in their ability to explain how different fishing motivations might interact within an individual, why particular motivations are prioritized, and how they might influence fisher behavior and attitudes. This study trialed a mixed methods approach to understanding fisher heterogeneity based primarily on motivations using a case study in NSW, Australia. This trial involved utilizing a person-centered approach known as Latent Class Analysis (LCA), followed by qualitative, in depth focus group discussions. This revealed five distinct fisher classes; Social fishers, Trophy Fishers Outdoor Enthusiasts, Generalists and Hunter-Gatherers, each with distinct and significantly different combinations of catch and non-catch-related motivations. The qualitative analysis sought to explore the intersection of motivations and attitudes towards management within and across the different fisher classes. The results highlighted the importance of more detailed examination of the intersection between motivations and attitudes in future LCA, with a particular focus on the potential influence of mastery (or challenge/experience) motivations on fisher attitudes towards marine and fisheries management approaches.

Keywords: Recreational fishing, motivations, attitudes, consumptive orientation, Latent Class Analysis; mixed methods

\section{Introduction}

Human dimensions researchers and fisheries managers have long recognized the value of understanding heterogeneity amongst recreational fishers (Hunt et al., 2013). Recreational fishers are a socially and culturally diverse group of people. The pastime has widespread appeal across the broad spectrum of society, with participants spanning a diversity of ages, genders, races and 
socioeconomic backgrounds (Floyd et al., 2006, Kyle et al., 2007). Fishers also act relatively autonomously, often with limited active management or monitoring, across large geographical areas. Management therefore needs to rely heavily on encouraging voluntary compliance with regulations, including through communication strategies (Leisher et al., 2012, Zorrilla-Pujana and Rossi, 2014, Hunt et al., 2013). Human dimensions research has traditionally explored fisher heterogeneity through research into the different reasons why people choose to fish, as well as attempts to categorize or segment fishers.

\subsection{Motivation to fish}

Understanding how and why people participate in recreational activities has been a focus of research amongst leisure studies researchers for decades (Manfredo and Driver, 1996). Motivation relates to social goals, or desired goal states, and is understood to provide insights into the most effective ways to minimize user conflicts, maximize user benefits and understand the consequences of leisure engagements (Manfredo and Driver, 1996, Clark et al., 2009). Human dimensions research into recreational fishing consistently recognizes the importance of fisher motivations in influencing decision making around catching and keeping fish, fisher satisfaction and responses to management interventions. The diverse reasons why people choose to fish are generally grouped into two broad categories: (1) Activity general (or non-catch-related), and (2) Activity specific (or catch-related) motivations (Arlinghaus, 2006).

General (or non-catch-related) reasons to fish encompass relaxation, escaping work and life demands, being with nature, learning new skills, and socialization (Arlinghaus, 2006, Anderson et al., 2007, Hunt and Ditton, 2001, Kuehn et al., 2013). While there are numerous types of activity general motivations referred to in the literature, these can be grouped under broad domains that are common to most recreational pursuits, including fishing.

1. Mastery, including intellectual factors, such as mental stimulation (Beard and Ragheb, 1983), achievement (Kuehn et al., 2013, Hunt and Ditton, 2001, White, 2008), competence (Dillard and Bates, 2011, Beard and Ragheb, 1983), competing or winning (Dillard and Bates, 2011) and challenge (Beardmore et al., 2011);

2. Social factors, whereby an individual is motivated by social interactions arising from the activity (Beard and Ragheb, 1983, White, 2008, Beardmore et al., 2011, Kuehn et al., 2013); including enhancing relationships (Dillard and Bates, 2011);

3. Escapism, including stimulus avoidance and relaxation. Where an individual pursues an activity to escape stressful situations including work and/or family demands (White, 2008, 
Dillard and Bates, 2011, Kuehn et al., 2013, Hunt and Ditton, 2001), or connect with nature (Kuehn et al., 2013, White, 2008, Beardmore et al., 2011, Hunt and Ditton, 2001).

Activity specific motivation reflects the value individuals place on pursuing, catching, and retaining fish, and is often referred to as consumptive orientation (Anderson et al., 2007). Previous research has typically examined consumptive orientation in relation to four domains, which reflect the importance of:

1. Catching 'something';

2. Catching large numbers of fish;

3. Catching large sized fish; and

4. Releasing caught fish (Anderson et al., 2007).

Understanding catch-related motivations is important because different sections of the angling community are likely to have different levels of consumptive orientation and thus could have varying implications for the resource (Fenichel et al., 2013). Consumptive orientation has also been found to be linked with outcomes such as satisfaction with fishing experiences (Arlinghaus, 2006) and levels of fishing avidity or commitment (Kyle et al., 2007, Sutton and Ditton, 2001). Despite this, catchrelated motivations have often been neglected in the literature in favor of more general non-catchrelated motivations that are considered the primary motivators of most fishers (Schramm and Gerard, 2004, Arlinghaus, 2006, Aas and Kaltenborn, 1995). Motivational preferences, however, appear to be highly contextual and influenced by factors including species targeted, locations fished and the other people involved in the fishing trips (Beardmore et al., 2011, Anderson et al., 2007). This suggests that catch and non-catch related aspects of the fishing experience interact in complex ways and may be prioritized differently depending on individual and contextual factors.

\subsection{Categorizing fishers}

In the human dimensions literature, attempts are often made to categorize (or segment) recreational fishers to understand the heterogeneous nature of this population (Hunt et al., 2013). Attempts to categorize fishers emerged out of broader leisure participation and involvement research conducted in the 1970s, when human dimensions researchers first proposed a specialization index for recreational fishers (Salz et al., 2001). This index hypothesized that fishers developed along a spectrum from novice to highly specialized as they became more experienced at fishing. A large body of research has since refined, expanded or built upon this approach (e.g. see Ditton and Loomis, 1992, Salz et al., 2001). The bulk of this research relies on large scale quantitative surveys to examine a presence or absence of a range of key variables amongst individual fishers. The 
insights gained through categorizing fishers has the potential to assist managers in developing targeted communication strategies, direct resources around active management more efficiently and improve understanding of how fishers will respond to changes in regulations or new management interventions.

Avidity, or frequency of fishing activity, plays a central role in determining fisher categorization. It is considered so important it has been tested as a potential surrogate measure of specialization levels (i.e. more avid fishers are more likely to be highly specialized) (Hawkins et al., 2009). Commitment to fishing is also critically important. In specialization studies, commitment has been examined through measures of financial expenditure, the time people dedicate to fishing and the role fishing plays in their personal identity and social networks (Salz et al., 2001, Schroeder et al., 2006). Other studies have examined fisher willingness to 'substitute' fishing for an alternative recreational pursuit (Ditton and Sutton, 2004), fisher orientation (extent to which the person identifies themselves as a fisher) and experience (level of experience and expertise in fishing) (Hawkins et al., 2009). Alternative categorization techniques, such as Sutton's 'centrality to lifestyle' scale (2003), also rely heavily on measures of commitment, including avidity, the importance of fishing to social connections and relationships, levels of expertise in fishing and the importance of fishing to an individual's sense of self or identity.

Research to date into fisher categorization has provided some insight into the diverse responses that fishers can have to management interventions or changes. For example, Li et al (2010) found that high centrality fishers in Central Queensland, Australia were more likely to be receptive to science communication and more interested in engaging in management processes. Specialization studies have consistently pointed to the higher importance placed on non-catch-related motivations amongst highly specialized fishers. This finding has not, however, translated into support for management approaches which allow fishing but remove the option of fulfilling catch-related motivations (e.g. through catch and release only areas) (Beardmore et al., 2011, Arlinghaus, 2006, Connelly et al., 2013). In addition, highly specialized fishers have been found to be environmentally conscious and supportive of active fisheries management such as limits on catch, but are often resistant to other protection measures such as Marine Protected Areas (MPAs), despite the fact that they are unlikely to have any impact on a fishers ability to pursue non-catch-related objectives (Martin et al., 2016, Salz and Loomis, 2004, Salz and Loomis, 2005, Voyer et al., 2013b). These apparent inconsistencies have been difficult to explain through quantitative surveys, especially given their heavy focus on avidity and commitment variables.

\subsection{Application of a Person-Centered Approach to understand fisher heterogeneity}


The vast majority of previous research attempting to categorize recreational fishers has utilized variable-based approaches. Commonly used analytic approaches such as regression and structural equation modelling are variable-centered because they examine the relationships among variables (Muthèn and Muthèn, 2000). These variable-based approaches have been applied widely in previous recreational fishing research, and have provided important insights into the nature of fishing motivations. These variable-based approaches are, however, limited in their ability to examine potential inter-individual differences, such as variations in types and levels of fishing motivations. In contrast, person-centered analyses attempt to capture the heterogeneity that exists in a population by finding distinct subgroups of individuals (Nylund et al., 2007). This is because, person-centered approaches such as cluster analysis and Latent Class Analysis (LCA) aim to identify meaningful groups of individuals based on a given set of variables (Muthèn and Muthèn, 2000). This has particular importance and relevance given the diversity of recreational fishers, the complexity of fishing motivations, and the potential for different types of fishing motivations to co-occur in unique ways. Moreover, understanding the complex inter-relationship between catch and non-catch-related motivations is likely to play a large role in determining fisher responses to different management approaches and fishing experiences (Beardmore et al., 2011). Understanding these interactions better has the potential to provide significant insights into some of the key questions facing fisheries managers around the world, including fishing satisfaction and management compliance and acceptance.

This study sought to investigate recreational fisher heterogeneity through the use of a mixed methods approach based around fisher motivations. In particular, the study sought to explore two central research questions:

1. Can categorization of fishers using a person centered approach based on motivation to fish provide robust and meaningful insights into fisher heterogeneity?

2. Can this categorization assist in better understanding attitudes and responses to fisheries and marine conservation management measures?

Two methodological approaches were employed. Firstly, an LCA on a large sample of Australian recreational fishers was used to identify distinct motivational subtypes. Secondly, qualitative focus groups were conducted to better understand these subtypes and their implications for fishing policies and regulation.

\subsubsection{Latent Class Analysis}

LCA is a particularly useful person-centered approach given its flexibility, ability to handle different variable types (e.g., nominal, ordinal, count, and continuous variables), and the availability of 
statistical criteria to inform the number of subgroups (or latent classes) (Vermunt and Magidson, 2002, Nylund et al., 2007). Approaches such as LCA have been widely used to investigate individual differences across a vast number of areas including substance use (Muthèn and Muthèn, 2000), health risk behaviors (Laska et al., 2009), psychological disorders (Kessler et al., 2005), marketing (Bhatnagar and Ghose, 2004), management (Robinson et al., 2016), and education (Pastor et al., 2007).

Person-centered approaches have rarely been utilized in the context of recreational fishing, but have the potential to provide important insights into the diversity of recreational fishing motivations. For example, recreational fishers are known to be a diverse group, with considerable variability in the types and strengths of motivations. LCA offers a statistical approach for capturing this diversity by identifying distinct subtypes of recreational fishers. This could have important practical implications by informing more tailored strategies to engage with recreational fishers, respond to their needs, and implement strategies to promote more sustainable and enjoyable fishing experiences.

The few available studies using person-centered approaches in recreational fishers indicate distinct subtypes of fishers on the basis of fishing satisfaction (Holland and Ditton, 1992), fishing preferences (Connelly et al., 2001), and consumptive orientation (Kyle et al., 2007). Kyle et al.'s (2001) study is particularly relevant to the present study given that consumptive orientation reflects activity specific motivations. Using cluster analysis - a person-centered approach that is related to LCA - Kyle et al. (2007) found four distinct consumptive orientation clusters in their sample of 430 US recreational fishers. These clusters were labelled (1) Lots 'o fish, (2) Bigguns, (3) Nothin', and (4) Keepers, and indicate that recreational fishers differ in relation to the type and level of consumptive orientation. This study sought to build upon the few studies in this area and provide a more comprehensive person-centered investigation of activity-general and activity-specific motivation in recreational fishers.

\subsubsection{Focus Groups}

The LCA analysis was supported by subsequent qualitative focus group discussions. There is surprisingly little qualitative research into recreational fishing in the existing literature despite the powerful role it can play in building new theory and providing fresh explanatory insights into management questions (Barclay et al., 2017). The small number of qualitative examinations of recreational fishers and fisher behavior point to the important role fishing can play in the formation of identity, particularly amongst men, and their relationships with each other and the natural world (Young et al., 2016, Voyer et al., 2013a, Voyer et al., 2013b). In this regard recreational fishing is likely to have many similarities with other nature based recreational pursuits, including surfing 
(Waitt, 2008, Waitt and Frazer, 2012, Waitt and Warren, 2008) and hunting (Adams, 2013), yet this has not been examined in detail to date. The focus groups provided two important roles in the overall methodological approach. Primarily, they sought to test and validate the categorization of fishers identified through the LCA, in order to ground truth the survey results and provide depth to these findings. A secondary function of the groups was to examine the link between categorization and attitudes and potential intersections between particular attitudes and motivations. This second component of the research was exploratory and designed to elicit fresh insights which, it was intended, would provide avenues for further qualitative and quantitative examination and investigation in the future.

\section{Methods}

The research involved two key components, incorporating two quantitative surveys delivered via telephone and internet and a series of qualitative focus groups. The data obtained through the quantitative surveys were analyzed through LCA and the motivational classes identified. The qualitative research then investigated these classes in greater depth, in order to ground truth the findings. They also explored how different motivational classes responded to key management concerns.

\subsection{Participants}

One of the significant challenges facing human dimensions researchers conducting recreational fishing surveys is obtaining a representative sample. Exact population sizes are difficult to determine and effective sampling strategies are constrained by problems of access and bias. For example, convenience sampling using online surveys are low cost, provide easy access to respondents and are simple to administer, however, they are also known to involve significant bias towards respondents who are particularly engaged in the topic area (Ethier et al., 2000). Online samples cannot be therefore be considered as representative, but can give insights into population subgroups - in this case highly avid fishers, or fishing enthusiasts. Random phone or mail surveys are known to have a greater level of representativeness but are also much more expensive, difficult to administer, and in the case of relatively small populations require very large sample sizes to reach an adequate number of respondents. They also have inherent problems with non-response bias and, in the case of phone surveys, possible bias towards older members of the population who still maintain fixed line phone connections (Ethier et al., 2000).

In NSW, Australia, where this study took place, there are an estimated 850,000 recreational fishers, equating to approximately $12 \%$ of the state (West et al., 2015). While the majority of recreational 
fishers in NSW require a recreational fishing license, exemptions exist for some sections of the community. This creates some difficulties in obtaining a truly representative sample of fishers in a cost effective way. In order to address these difficulties, a combination of two approaches were employed to recruit a sample of fishers, in order to sample a cross section of fishers from less avid to highly avid, and licensed and unlicensed. Given the inherent strengths and weaknesses of the two sampling approaches the results cannot be considered fully representative of the fishing population. The purpose of this study is therefore not to make generalizable claims about the motivational profiles of NSW anglers, but rather to detail the development and application of a method to categorize anglers into homogenous sub-groups based on differences in motives for participation. Thus, the findings of this study are limited to the sample as no inferences can be made regarding the broader population. The methods detailed, however, have the potential for broader application in studies of motivation in recreational pursuits.

Firstly, a telephone survey method was used to survey approximately 300 non-licensed anglers and an additional 300 licensed anglers. These participants were selected in the following ways:

1) Non- licenced anglers: A sample of 600 recreational fishers not requiring a licence (eg. concession holders, pensioners) had been previously identified in a State-wide expenditure project which involved a state wide random phone survey (Mcllgorm and Pepperell, 2013). This was used to obtain responses from 300 non-licenced anglers.

2) Holders of a recreational fishing licence: A sub-sample of licence holders in the NSW Department of Primary Industries (DPI) Recreational Fishing Licence database was surveyed to obtain responses from 300 licenced anglers. These were stratified in proportion to the actual number of 3 day, monthly, 1 year and 3 year licence holders in the licensed population.

Secondly, an internet survey method was used to supplement the telephone survey primarily amongst licensed anglers using a convenience sampling approach. The respondents were obtained through placing a short article on the project in the DPI recreational fishing newsletter which is distributed to those on the recreational fishing license data base. This meant those reading the article had the opportunity to log on to the link given and to complete the internet-based survey. The approach secured an additional 813 responses.

Recruitment of participants for focus groups was linked to the internet and telephone surveys, which included a question asking if respondents would be interested in being involved in a focus group discussion. The resulting list was classified according to their motivational class identified through 
the LCA and the focus groups aimed to include participants from across all the identified motivational classes.

\subsection{Latent Class Analysis}

A quantitative survey was developed which examined the range of variables commonly employed in human dimensions research into recreational fishing. Established scales were used to assess activity general and activity specific motivations for recreational fishers. These surveys focused primarily on addressing the first of the two research questions: Can categorization of fishers using a person centered approach based on motivation to fish provide robust and meaningful insights into fisher heterogeneity?

Activity general motivations were assessed using five items adapted from a scale developed by Fedler and Ditton (1994). In order to reduce the time burden for the phone survey, this scale was shortened by removing some items (e.g., items that overlap with those included in the consumptive orientation questionnaire), combining items that assessed similar domains (e.g., "to be with friends" and "for family recreation" - these both reflect socialization), and reducing the response categories from five to three. The modified items (Table 1) asked participants to rate the importance of different aspects of fishing, including the opportunity for relaxation, to be with friends and family, and to learn new skills.

Activity specific motivations were assessed using six items from the scale developed by Graefe (1980) and modified by Fisher (1997). Again, the full scale was not used in order to minimize participant burden, with items selected on the basis of face validity, high factor loadings reported in previous research (e.g., Fisher, 1997), and Australian research indicating important catch-related aspects for recreational fishers (West et al., 2015). The included items (see Table 1) reflected the four domains of consumptive orientation: "catching something", "catching large fish", "catching numbers of fish", and "consuming caught fish".

\section{[INSERT TABLE 1]}

Fishing involvement was assessed in relation to centrality-to-lifestyle and fishing frequency. Centrality-to-lifestyle was assessed using the nine-item scale developed by Kim et al. (1997) and adapted to the recreational fishing context by Sutton (2003). This scale assesses how central the fishing experience is to an individual's lifestyle (e.g., "I find that a lot of my life is organised around fishing"), with items assessed on a 5-point likert scale from strongly disagree to strongly agree. As recommended in the literature (e.g., Sutton , 2003; Li et al., 2010), responses were summed and averaged to create an index of centrality (Cronbach $\alpha=.87$ ). In regards to fishing frequency, 
individuals were asked how many days they had fished in saltwater locations and freshwater locations over the past year. This provided an indication of annual fishing frequency on a continuous scale.

The surveys also assessed some key demographic characteristics that may be related to recreational fishing including age (continuous variable), gender, marital status (partnered/married versus single), and country of birth (coded as Australia versus other country).

LCA was performed to identify subgroups of fishers based on the 11 items described above assessing different activity specific and activity general aspects of fishing. The LCA was performed using Mplus version 6.11 (Muthèn \& Muthèn, 2010) and consisted of two main phases. The first phase was to identify the optimal number of distinct subgroups in the combined sample of recreational fishers. This involved testing a series of models that specified a different number of latent classes. That is, a model with 1 latent class was tested first, followed by 2 latent classes, and so on until the optimal number of latent classes was identified. Given the ordinal nature of the response categories for each item, each item was treated as a categorical indicator in the analyses.

As noted above, the aim of LCA is to identify the smallest number of latent classes that can describe the associations among a set of observed variables (Muthén \& Muthén, 2000). The selection of the number of latent classes was informed by taking several factors into consideration. Indicators of model fit - Akaike Information Criteria (AIC), Bayesian Information Criteria (BIC), and sample size adjusted BIC - were compared across models, with lower relative values indicating an improved model fit (Nylund et al., 2007). Bootstrap likelihood ratio tests were also used to compare statistical fit between two consecutive models (e.g., a model with 4 classes compared with a model with 3 classes) (Nylund et al., 2007). While these statistical indicators are informative, it is also important to inspect the characteristics of the identified classes to ensure that they are distinctive and meaningful (Ram and Grimm, 2009). Relying on statistical criteria alone can overestimate the number of latent classes particularly with a larger sample size, and lead to the identification of classes that are not clearly distinct from one another.

Classification accuracy was also inspected (reflected by entropy) along with the size of the identified latent classes (Celeux and Soromenho, 1996). Classification accuracy is important, because low accuracy means that there is considerable overlap between at least 2 classes. Although there are no definitive cut-offs for classification accuracy, it has been suggested that models with entropy levels below .80 need to be treated with caution (Celeux and Soromenho, 1996). Class size is also an important consideration, since very small classes may not be meaningful. 
Once the number of latent classes was identified, a full LCA model was examined that specified the relevant number of latent classes and modelled covariates as predictors of class membership. In this paper, the following covariates were examined: sample (phone versus internet sample), age (continuous), gender, country of birth (Australia versus other country).

\subsection{Focus group interviews}

Focus group discussions were semi-structured and centered on both of the stated research questions. For the first research question the focus group sought to test and validate the categorization of fishers identified through the Latent Class Analysis. They did so by revisiting major questions explored through the quantitative survey, especially in relation to catch and non-catch related motivations.

The second research question, which sought to examine the link between categorization and attitudes towards fisheries management measures, was more exploratory. This reflects that thematic areas relating to attitudes were emergent through the course of the questionnaire and focus groups and there are no established quantitative scales through which to identify which particular attitudes might be of relevance or whether and how they might intersect with motivations. A grounded theory approach was subsequently used as means of identifying new ideas or theory that could be tested in subsequent research (Glaser and Strauss, 1967). The focus groups sought to determine whether particular attitudes could be associated with the identified classes of fishers. Further to this they sought to explore whether some attitudes or perceptions intersected with any of the identified motivational domains. The attitudinal questions asked in the focus groups were determined by the responses of survey participants to a final open ended question in the survey, which asked respondents to add any additional comments or statements relating to recreational fishing in NSW. The most commonly mentioned concerns in these comments related to commercial fishing and general enforcement or compliance (11\% each), followed by statements both supporting and criticising Marine Protected Areas (6.5\%). These three areas of concern were explored in greater detail through the focus group discussions to assess whether there were any links between the motivation profiles of the identified sub-groups and attitudes towards fisheries management.

Prior to commencement of each focus group the project objectives were explained and a detailed consent form provided to each participant to complete. All focus groups were between 1.5 and $2 \mathrm{hrs}$ long and were audio and video recorded. Audio recordings were subsequently transcribed verbatim and the results analyzed using Nvivo 10 qualitative research software. This involved coding focus 
group discussions into key themes which emerged from the discussions (Miles and Huberman, 1994).

\section{Results}

\subsection{Participants}

In total 1,436 responses were received from the two surveys, 623 from the phone survey $(85.6 \%$ male) and 813 from the internet survey (92.3\% male). The average days fished were significantly higher in the internet $(M=44.52 ; S D=60.99)$ than phone sample survey results $(M=24.88 ; S D=$ $33.45 ; p<.001)$, indicating that the internet survey respondents were more avid than the phone survey respondents. A range of additional significant differences between the two samples were identified and these are outlined in Table 2. In general they indicate that the internet respondents had a higher percentage of males and were, on average younger, fished significantly more days a year and had higher 'centrality to lifestyle'.

\section{[INSERT TABLE 2]}

Direct comparisons with the broader NSW fishing population are not possible given differences in sampling strategies, however, a study by West et al. (2015) indicated that the majority of NSW fishers are male (70\%), aged between $30-44 y e a r s ~(26 \%)$ and fish in saltwater (79\%). Fisher days were estimated at 4.3 days per fisher/year overall. Another study by Mcllgorm and Pepperell (2013) estimated a much higher average of 14.6 days per year. The phone and internet samples of this study indicate higher levels of avidity overall (Table 2), suggesting our sample was significantly more avid across both recruitment methods. The greater representation of females in the phone survey suggests it is a more representative sample of the fishing population in relation to gender, however this sample also indicates a slight bias towards older anglers, with the internet survey closer to the NSW average. No data are available on education or income levels for the NSW fisher population.

All the focus group participants were sourced from the respondents to the internet survey, as there was insufficient interest from the phone survey respondents. $463(57 \%)$ participants from the internet survey indicated they would be interested in further involvement and nominated a location in which they would be able to attend a focus group. From this list, 182 people nominated the Sydney region and 52 nominated the Wollongong region. These respondents were invited to take part in focus groups in these locations. Six focus groups, consisting of 34 participants (with an average of six participants per session) were conducted. Consistent with the survey results the majority of participants were male (89\%) and ages ranged between 24 and 78 . 


\subsection{Fisher classification - LCA and focus group results}

The results of the LCA indicated are shown in Table 3, including the model fit criteria, BLRT, and entropy levels for models specifying one to six latent classes. While the BLRT was significant for all models tested (suggesting an improved model fit between consecutive models), the BIC (a particularly robust indicator of model fit) increased from the five-class to the six-class model. Furthermore, when the six-class model was inspected it was noted that the additional class overlapped with some of the classes identified in the five-class model. For these reasons, the fiveclass model was selected.

[INSERT TABLE 3]

The characteristics of the five classes are shown in Table 4 and Figure 1. The five classes were labelled Social fishers, Trophy Fishers, Outdoor enthusiasts, Generalists and Hunter Gatherers in response to their motivational priorities

\section{[INSERT TABLE 4]}

[INSERT FIGURE 1]

A number of significant differences were detected between the phone and internet surveys, and in relation to a range of demographic characteristics across the five identified classes. Social fishers and generalists had lower levels of centrality to lifestyle, fished less frequently, were more likely to be female and to have been found in the phone sample. Trophy fishers and Escapists had higher centrality and fishing frequency and were more likely to have been found in the internet sample (Table 5).

\section{[INSERT TABLE 5]}

The focus groups were designed around these five identified classes and aimed to ensure a sample of all motivational classes were included in this stage of the research (Table 6). The extent to which the participants identified with each of the motivational factors measured through the quantitative surveys was analyzed through a count of the references they made to that concept. These motivational factors were grouped against six key categories, which were consistent with those used in the LCA:

1. Mastery (or challenge)

2. Socialization

3. Escapism (or relaxation) 
4. Importance of catching large fish

5. Importance of catching something

6. Importance of keeping fish

The importance of catching a 'large number of fish' was not specifically discussed in the focus groups due to time constraints so that factor was excluded from the analysis. To standardize the responses, these coding references were examined as a proportion of the total number of coding references within each class. In other words, the total number of contributions of comments made by members of each class to the focus group discussions was quantified and then coded across the pre-identified motivational factors. The results of this analysis are contained in Figure 2.

\section{[INSERT TABLE 6]}

\section{[INSERT FIGURE 2]}

In general the focus group discussions validated the differences between the classes identified through the LCA, however they were also able to provide some additional insight or nuance to the findings not necessarily picked up in the LCA (Table 7). These particularly related to the different ways in which specific motivations were manifested within individuals. For example, mastery aspects of fishing for Trophy Fishers linked strongly with beating personal bests in terms of fish size, whilst in Outdoor Enthusiasts it was framed more about competing or challenging oneself against nature, and Hunter Gatherers talked more about the 'gamble' of fishing and trying ones luck.

\section{[INSERT TABLE 7]}

\subsection{Exploring the link between motivation and attitudes}

The focus groups also sought to explore possible links between different types of motivation and attitudes towards fisheries management. As previously mentioned this stage of the process was exploratory and aimed to uncover new ideas, research questions and insights which might be further explored in subsequent research and assist efforts to make systematic predictions about angler attitudes and behaviors. The analysis therefore sought to uncover patterns or new ideas that could be tested in future research in order to better understand the link between motivation and attitudes.

Coding was conducted of focus group transcripts to identify key themes. These themes were examined to across the five fisher classes. No clear patterns, including dominance of particular attitudes, were detected within or across classes (Mcllgorm et al., 2016). The themes were then examined across different motivational categories. The clearest trends emerged in the analysis of 
the intersection of mastery motivations and attitudes. Mastery was important to varying extents to $65 \%$ of the focus group participants (Table 8), and was found in varying degrees within all classes, as suggested by the LCA.

\section{[INSERT TABLE 8]}

The qualitative analysis suggests that there maybe be a relationship between the strength of mastery motivations and particular ideas or themes (Table 9). For example, the dominant themes amongst mastery motivated fishers related to the impacts of both commercial fishing and MPAs on their own fishing experiences, including concerns over being 'locked out' of fishing areas through area closures, or a desire to see commercial fishing curtailed to give greater access to recreational fishers.

Fishers less motivated by mastery aspects of fishing were also concerned about the environmental impacts of commercial fishing but were less likely to relate it to their local situation or their own fishing experiences. Instead they referred to international examples of over fishing or concerns over industrial scale fishing. They also expressed concern or confusion about MPA zoning boundaries and a fear that they would inadvertently break the rules. In addition, they expressed a lack of trust in the processes by which these management arrangements were devised.

\section{[INSERT TABLE 9]}

\section{Discussion}

This trial, based in NSW Australia, demonstrated the existence of distinct classes of recreational fishers on the basis of a range of activity general and activity specific motivations, encompassing important motivational domains such as escapism, mastery, catching large fish, and consuming caught fish. While attempts to categorize fishers are not new in human dimensions research, person-centered approaches have rarely been used to capture the heterogeneity of this population. The use of LCA in this paper allowed for a more nuanced understanding of the interplay that exists between the many different types of motivational domains that have been previously examined in human dimensions research into recreational fishing, and in particular placed motivations at the center of the categorization process. Additional insight was provided by exploring these variables in a more in-depth way, through qualitative fieldwork.

\subsection{A new way to categorize fishers according to motivations}

This study demonstrates that categorization of fishers using a person centered approach based on motivation to fish does provide robust and meaningful insights into fisher heterogeneity. The mixed 
methods approach identified and validated five distinct classes of recreational fishers in NSW, Australia. Social Fishers (21.7\%) and Generalist Fishers (14.4\%) had lower levels of avidity and centrality to lifestyle and were primarily motivated by the escapism and social aspects of fishing. Hunter Gatherers (22.6\%) were a unique class in that they have high levels of consumptive orientation. Finally, the trophy fishers (12.5\%) and outdoor enthusiasts (28.9\%) had greater association with the more avid internet survey, demonstrated higher levels of fishing frequency and were more interested in the challenge and mastery aspects of the fishing experience.

The identification of distinct motivational classes, representing unique combinations of activity specific and activity general motivation is consistent with studies examining other recreational activities (Alexandris et al., 2009, Hennigs and Hallmann, 2015, Ritchie et al., 2010). Although LCA has rarely been used to investigate recreational fishing, the findings of this study are also consistent with the results of Beardmore et al. (2011) and Kyle et al. (2007) who demonstrated that catch and non-catch motivations interact within individuals in diverse but measureable ways.

While traditional, variable based categorization approaches built primarily around measures of avidity and commitment provide important insights into different levels of interest in the recreational pursuit of fishing, a person centered approach based around motivations has potential to explain the reasons behind these levels of interest. This is significant because while recreational fishing is recognized as an example of a linked social-ecological system, there has been a 'siloed' approach to the scientific versus human dimensions of recreational fisheries management. Understanding the links between these two dimensions, and in particular the feedback responses of fishers to management interventions and ecological changes, will be critical for the continued health of this linked system (Arlinghaus et al., 2013). For example, one aspect of the social-ecological system that has been neglected in scientific literature is the influence of heterogeneity in catch effort and harvest levels (Cabanellas-Reboredo et al., 2017). This trial identified a distinct group of recreational fishers within the sample with relatively high levels of consumptive orientation (i.e. hunter gatherers). Understanding the motivational profile of this class of fisher may provide useful insights into their impact on ecological health and their response to ecological and management changes. For example, this group may be responsible for greater catch harvest than other groups, and they may also be more likely to be concerned with restrictions on catch and effort, and at risk of non-compliance with these restrictions. Efforts to build voluntary compliance with fishing regulations may therefore benefit from a greater level of attention and understanding of the motivational profile of this group. 
This research suggests some links between the motivational profiles of fishers and key aspects of behaviour such as site selection (Hunt, 2005). For example, the motivational profile of Trophy Fishers suggests that this group may be more likely to be sensitive to over-crowding concerns given their high interest in escapism and mastery, and low interest in the socialization aspects of fishing demonstrated in the focus groups as an interest in solitary fishing in remote locations. This is of significance for spatial planning exercises which might displace fishing and lead to greater numbers of fishers in more remote areas (De Freitas et al., 2013, Voyer et al., 2013b).

Insights such as these can assist fisheries managers by highlighting the different approaches that may be necessary to engage different classes of fishers and build support for management changes. Education and promotional campaigns across all classes would benefit from tapping into the different motivational factors which influence their involvement. For example, Trophy fishers with high interest in mastery may respond best to messaging focusing on challenge and skill development, while social fishers and generalists may be more receptive to simple, informative messages which build on themes around escape, relaxation and social networks. These insights might be especially beneficial to campaigns to recruit and retain new entrants by identifying the diverse ways the sport might appeal to different people within the broader community.

It is therefore recommended that further trials of the LCA method be conducted to refine and develop this approach within a recreational fishing context. LCA is currently used in a range of disciplinary areas including health studies, marketing, consumer behavior and leisure studies and has significant potential to provide new insights into the human dimension of recreational fisheries. In addition the mixed methods approach, incorporating qualitative analysis, was a beneficial component of this research.

The focus groups were able to validate and provide depth to the LCA by allowing a more detailed understanding of how different motivations manifested themselves in different ways amongst individuals in each class. For example, some key differences in the way mastery motivations were pursued across different classes were detected. Trophy Fishers appeared to focus on chasing the biggest fish they could whilst Outdoor Enthusiasts enjoyed challenging themselves against nature and against the fish, not necessarily chasing big fish. That is, Outdoor Enthusiasts did not necessarily chase big fish, but rather chased new nature based experiences. Hunter Gatherers focused less on skill development and more on the 'gamble' of fishing. Further investigation of the mastery motivational domain may be worthwhile in order to better understand the ways these aspects of fishing intersect and interact with the other motivational domains. This may also be important when considering the influence of motivation to fish on fisher attitudes. 


\subsection{The intersection between motivation and attitudes}

Distinct differences in attitudes between classes were not detected in the focus groups, however there were differences in attitudes on the basis of preferences around the mastery aspects of fishing. This suggests that a more detailed investigation of the intersection of motivational classes and attitudes is warranted, given different classes prioritized mastery differently. These results highlight the potential for a more in-depth, larger scale and representative investigation of fisher attitudes to reveal key differences between the fisher classes.

The combined results of the LCA and focus groups highlighted the complexity of recreational fishing motivations and that mastery is a diverse motivation category capturing efforts by fishers to maximize opportunities to challenge themselves, seek different experiences, or achieve personal bests. The focus group findings showed some consistencies in the way fishers felt about particular management approaches, which appeared to correspond most strongly to mastery motivations. In particular these fishers appeared to have felt more impacted by activities which they perceived to limit the opportunities most related to mastery. While these fishers were often less interested in keeping fish, their opposition to activities which limited their opportunities to target or land fish, such as area closures or competing uses, suggests that the loss of the potential fishing experience was of concern. Consistent with many studies that have examined fisher attitudes towards area closures, the focus group participants often opposed MPA creation but were supportive of regulations enforcing limits on size and catch, which control their take (i.e. what they can keep) but not their ability to catch something (i.e. whether they can catch but release) (Arlinghaus, 2006, Martin et al., 2016, Voyer et al., 2013b, Salz and Loomis, 2004, Salz and Loomis, 2005). These alternative forms of restriction may be tolerated or embraced because they still allow individual choice and control over the decision as to whether to target, retain or return a fish. In other words, they do not limit their opportunity to achieve a personal best, experience a new nature based challenge or 'try their luck' in a new or different area. Closed areas and commercial fishing, by way of contrast, may be seen as fundamental barriers to achieving the fulfillment of these motivations by restricting access or, in the case of commercial fishers, providing an 'unfair' advantage to others in accessing the fish.

These results indicate that, despite the different 'manifestations' of mastery, this motivational domain may play an important role in influencing fisher attitudes within and across fisher classes. The incorporation of attitudinal scales into future LCA studies, as well as more detailed qualitative analysis may provide greater insight into whether discernable differences can be detected across fish 
classes according to the extent to which they prioritize mastery. This is an important area for future research inquiry that can build and improve upon the trial undertaken in NSW.

\subsection{Future research}

Whilst this study provided a number of useful insights, future research is needed to confirm the presence and nature of these classes, and clarify their implications for fishing management. In particular future research would need to address issues with ensuring a representative sample and would benefit from the incorporation of attitudinal scales into the LCA, in order to further test the link between attitudes and motivations. A more detailed examination of different forms of mastery motivations may also provide useful insights into the differences that exist across fisher classes.

This paper examined data collected using two recruitment methods: phone survey and internet survey. It is feasible that these reflect two meaningfully different samples of recreational fishers within the population of recreational fishers in NSW. Based on our data, the phone survey sample had lower levels of avidity and centrality compared with the internet sample. These two samples also had strong relationships with class membership. In particular, individuals from the phone survey were statistically more likely to be classed as Social Fishers and Generalists, whereas those from the internet survey were more likely to be classed as Trophy Fishers, Hunter Gatherers, and Outdoor Enthusiasts. Recruiting representative samples is a major challenge, and the two recruitment approaches provide a useful insight into the diversity of recreational fishers. However, the sample is unlikely to be representative and thus the precise nature of the identified motivational classes may be different in a representative sample. Thus, more research is needed to understand the nature of distinct motivational patterns in representative samples.

The results of the qualitative focus groups also require additional investigation in order to validate and test the ideas that emerged through this analysis, particularly given some classes were underrepresented in the focus groups. The model employed in this study, whereby participants were recruited through the online survey, was found to be highly effective at engaging avid fishers but alternative techniques may be required for other, less enthusiastic fishers. The findings provided in this paper outline potential new avenues for inquiry and investigations on a larger scale, with key ideas able to be incorporated into future quantitative and qualitative human dimensions research.

\section{Conclusion}

The diverse reasons why people fish are likely to influence the way they respond to measures which impact or interact with their fishing experience. The mixed methods approach employed in this study uncovered a range of new insights which have potential to shed further light on the 
heterogeneity that exists within the recreational fishing population. These insights have the potential to drive a more strategic approach to engaging fishers, one which better recognizes the motivations that drive fishers and how these motivations are potentially impacted by different management interventions. Education campaigns may also benefit by allowing for more effective engagement by tapping into the different motivational classes and needs of fishers.

\section{Acknowledgements}

The Project team would like to acknowledge the assistance and advice of NSW DPI in disseminating and promoting the online survey which formed the basis of this study. Thanks also to the many recreational fishers who gave up their time to participate in the focus groups, complete the questionnaire and provide feedback on the project findings. Thanks also to the two anonymous reviewers who provided useful and constructive feedback which contributed significantly to the manuscript. The full report for this study can be obtained by contacting the corresponding author.

\section{Funding source}

This work was supported by the NSW Department of Primary Industries, Recreational Fishing Trust.

\section{References}

AAS, O. \& KALTENBORN, B. P. 1995. Consumptive orientation of anglers in Engerdal, Norway. . Environmental Management, 19, 751 - 761.

ADAMS, M. 2013. "Redneck, Barbaric, Cashed up Bogan? I Don't Think So": Hunting and Nature in Australia. Environmental Humanities, Vol 2, Pp 43-56 (2013), 43.

ALEXANDRIS, K., KOUTHOURIS, C., FUNK, D. \& GIOVANI, C. 2009. Segmenting Winter Sport Tourists by Motivation: The case of recreational skiers. Journal of Hospitality Marketing \& Management, 18, 480 - 499.

ANDERSON, D. K., DITTON, R. B. \& HUNT, K. M. 2007. Measuring Angler Attitudes Toward CatchRelated Aspects of Fishing. Human Dimensions of Wildlife, 12, 181-191.

ARLINGHAUS, R. 2006. On the Apparently Striking Disconnect between Motivation and Satisfaction in Recreational Fishing: The Case of Catch Orientation of German Anglers. North American Journal of Fisheries Management, 26, 592-605.

ARLINGHAUS, R., COOKE, S. J. \& POTTS, W. 2013. Towards resilient recreational fisheries on a global scale through improved understanding of fish and fisher behaviour. Fisheries Management \& Ecology, 20, 91-98.

BARCLAY, K., VOYER, M., MAZUR, N., PAYNE, A. M., MAULI, S., KINCH, J., FABINYI, M. \& SMITH, G. 2017. The importance of qualitative social research for effective fisheries management. Fisheries Research, 186, Part 2, 426-438.

BEARD, J. G. \& RAGHEB, M. G. 1983. Measuring leisure motivation. Journal of Leisure Research, 15, 219-228.

BEARDMORE, B., HAIDER, W., HUNT, L. M. \& ARLINGHAUS, R. 2011. The Importance of Trip Context for Determining Primary Angler Motivations: Are More Specialized Anglers More CatchOriented than Previously Believed? North American Journal of Fisheries Management, 31, 861-879. 
BHATNAGAR, A. \& GHOSE, S. 2004. A latent class segmentation analysis of e-shoppers. Journal of Business Research, 57, 758 - 767.

CABANELLAS-REBOREDO, M., PALMER, M., ALÓS, J. \& MORALES-NIN, B. 2017. Estimating harvest and its uncertainty in heterogeneous recreational fisheries. Fisheries Research, 188, 100-111.

CELEUX, G. \& SOROMENHO, G. 1996. An entropy criterion for assessing the number of clusters in a mixture model. . Journal of Classification,, 13, 195 - 212.

CLARK, R. N., HENDEE, J. C. \& CAMPBELL, F. L. 2009. Values, Behavior, and Conflict in Modern Camping Culture. Journal of Leisure Research, 41, 377-393.

CONNELLY, N. A., KEELER, S. \& KNUTH, B. A. 2013. Understanding Angler Preferences for Species and Water Bodies: Importance for New York's Future Fisheries Management. Human Dimensions of Wildlife, 18, 386-402.

CONNELLY, N. A., KNUTH, B. A. \& BROWN, T. L. 2001. An angler typology based on angler fishing preferences. . Transactions of the American Fisheries Society, 130, 130 - 137.

DE FREITAS, D. M., SUTTON, S. G., MOLONEY, J. M., LÉDÉE, E. J. I. \& TOBIN, R. C. 2013. Spatial substitution strategies of recreational fishers in response to zoning changes in the Great Barrier Reef Marine Park. Marine Policy, 40, 145-153.

DILLARD, J. E. \& BATES, D. L. 2011. Leisure motivation revisited: Why people recreate. Managing Leisure, 16, 253 - 268.

DITTON, R. B. \& LOOMIS, D. K. 1992. Recreation specialization: Re-conceptualization from a social worlds perspective. Journal of Leisure Research, 24, 33.

DITTON, R. B. \& SUTTON, S. G. 2004. Substitutability in Recreational Fishing. Human Dimensions of Wildlife, 9, 87-102.

ETHIER, R. G., POE, G. L., SCHULZE, W. D. \& CLARK, J. 2000. A comparison of hypothetical phone and mail contingent valuation responses for green-pricing electricity programmes. . Land Economist, 76, 54-67.

FENICHEL, E. P., ABBOTT, J. K. \& HUANG, B. 2013. Modelling angler behaviour as a part of the management system: synthesizing a multi-disciplinary literature. Fish and Fisheries, 14, 137157.

FISHER, M. R. 1997. Segmentation of the Angler Population by Catch Preference, Participation, and Experience: A Management-Oriented Application of Recreation Specialization. North American Journal of Fisheries Management, 17, 1-10.

FLOYD, M. F., NICHOLAS, L., LEE, I., LEE, J.-H. \& SCOTT, D. 2006. Social Stratification in Recreational Fishing Participation: Research and Policy Implications. Leisure Sciences, 28, 351-368.

GLASER, B. G. \& STRAUSS, A. L. 1967. The discovery of grounded theory : strategies for qualitative research Chicago, Aldine Pub. Co.

HAWKINS, C., LOOMIS, D. K. \& SALZ, R. J. 2009. A Replication of the Internal Validity and Reliability of a Multivariable Index to Measure Recreation Specialization. Human Dimensions of Wildlife, 14, 293-300.

HENNIGS, B. \& HALLMANN, K. 2015. A motivation-based segmentation study of kitesurfers and windsurfers. Managing Sport and Leisure, 20, $117-134$.

HOLLAND, S. M. \& DITTON, R. B. 1992. Fishing Trip Satisfaction: A Typology of Anglers. North American Journal of Fisheries Management, 12, 28-33.

HUNT, K. M. \& DITTON, R. B. 2001. Perceived benefits of recreational fishing to Hispanic-American and Anglo anglers. Human Dimensions of Wildlife, 6, 153-172.

HUNT, L. M. 2005. Recreational Fishing Site Choice Models: Insights and Future Opportunities. Human Dimensions of Wildlife, 10, 153-172.

HUNT, L. M., SUTTON, S. G. \& ARLINGHAUS, R. 2013. Illustrating the critical role of human dimensions research for understanding and managing recreational fisheries within a socialecological system framework. Fisheries Management and Ecology, 20, 111-124. 
KESSLER, R. C., CHIU, W. T., DEMLER, O. \& WALTERS, E. E. 2005. Prevalence, severity, and comorbidity of 12-month DSM-IV disorders in the National Comorbidity Survey replication. Archives of General Psychiatry, 62.

KUEHN, D., LUZADIS, V. \& BRINCKA, M. 2013. An Analysis of the Factors Influencing Fishing Participation by Resident Anglers. Human Dimensions of Wildlife, 18, 322-339.

KYLE, G., NORMAN, W., JODICE, L., GRAEFE, A. \& MARSINKO, A. 2007. Segmenting Anglers Using Their Consumptive Orientation Profiles. Human Dimensions of Wildlife, 12, 115-132.

LASKA, M. N., PASCH, K. E., LUST, K., STORY, M. \& EHLINGER, E. 2009. Latent class analysis of lifestyle characteristics and health risk behaviors among college youth. Prevention Science, 10.

LEISHER, C., MANGUBHAI, S., HESS, S., WIDODO, H., SOEKIRMAN, T., TJOE, S., WAWIYAI, S., NEIL LARSEN, S., RUMETNA, L., HALIM, A. \& SANJAYAN, M. 2012. Measuring the benefits and costs of community education and outreach in marine protected areas. Marine Policy, 36, 1005-1011.

LI, O., SUTTON, S. G. \& TYNAN, L. 2010. Communicating Scientific Information to Recreational Fishers. Human Dimensions of Wildlife, 15, 106-118.

MANFREDO, M. J. \& DRIVER, B. L. 1996. Measuring leisure motivation: A meta-analysis of the. Journal of Leisure Research, 28, 188.

MARTIN, C. L., MOMTAZ, S., JORDAN, A. \& MOLTSCHANIWSKYJ, N. A. 2016. Exploring recreational fishers' perceptions, attitudes, and support towards a multiple-use marine protected area six years after implementation. Marine Policy, 73, 138-145.

MCILGORM, A. \& PEPPERELL, J. 2013. Developing a cost effective state wide expenditure survey method to measure the economic contribution of the recreational fishing sector in NSW in 2012. A report to the NSW Recreational Fishing Trust, NSW Department of Primary Industries. Australian National Centre for Ocean Resources and Security (ANCORS), University of Wollongong.

MCILGORM, A., VOYER, M., MAGEE, C. A., PEPPERELL, J., O'TOOLE, E. \& LI, O. 2016. Improving our understanding of the motivations and attitudes towards fisheries management of recreational fishers in NSW. . Report to New South Wales Department of Primary Industry Recreational Fishing Trusts. Wollongong: Australian National Centre for Ocean Resources and Security (ANCORS).

MILES, M. B. \& HUBERMAN, A. M. 1994. Qualitative data analysis : an expanded sourcebook, Thousand Oaks, Sage Publications.

MUTHÈN, B. \& MUTHÈN, L. K. 2000. Integrating person-centred and variable-cented analyses: Growth mixture modeling with latent trajectory classes. Alcoholism: Clinical and Experimental Research, 24.

NYLUND, K. L., ASPAROUHOV, T. \& MUTHEN, B. O. 2007. Deciding on the number of classes in Latent Class Analysis and Growth Mixture Modeling: A Monte Carlo Simulation Study. . Structural Equation Modeling 14, 535-569.

PASTOR, D. A., BARRON, K. E., MILLER, B. J. \& DAVIS, S. L. 2007. A Latent profile analysis of college students' achievement goal orientation. Contemporary Educational Psychology, 32.

RAM, N. \& GRIMM, K. J. 2009. Growth mixture modeling: A method for identifying differences in longitudinal change among unobserved groups. International Journal of Behavioral Development, 33, 565-576.

RITCHIE, B. W., TKACZYNSKI, A. \& FAULKS, P. 2010. Understanding the motivation and travel behavior of cycle tourists using involvement profiles. Journal of Travel \& Tourism Marketing, $27,409-425$.

ROBINSON, L. D., MAGEE, C. A. \& CAPUTI, P. 2016. Work-to-family profiles, family structure and burnout in mothers. Journal of Managerial Psychology, 31.

SALZ, R. J. \& LOOMIS, D. K. 2004. Saltwater Anglers' attitudes towards marine protected areas. Fisheries, 29, 10-17. 
SALZ, R. J. \& LOOMIS, D. K. 2005. Recreation Specialization and Anglers' Attitudes Towards Restricted Fishing Areas. Human Dimensions of Wildlife, 10, 187-199.

SALZ, R. J., LOOMIS, D. K. \& FINN, K. L. 2001. Development and Validation of a Specialization Index and Testing of Specialization Theory. Human Dimensions of Wildlife, 6, 239-258.

SCHRAMM, H. L. \& GERARD, P. D. 2004. Temporal changes in fishing motivation among fishing club anglers in the United States. Fisheries Management and Ecology, 11, 312-321.

SCHROEDER, S. A., FULTON, D. C., CURRIE, L. \& GOEMAN, T. 2006. He Said, She Said: Gender and Angling Specialization, Motivations, Ethics, and Behaviors*. Human Dimensions of Wildlife, 11, 301-315.

SUTTON, S. 2003. Personal and Situational Determinants of Catch-and-Release Choice of Freshwater Anglers. Human Dimensions of Wildlife, 8, 109-126.

SUTTON, S. G. \& DITTON, R. B. 2001. Understanding Catch-and-Release Behavior Among U.S. Atlantic Bluefin Tuna Anglers. Human Dimensions of Wildlife, 6, 49-66.

VERMUNT, J. K. \& MAGIDSON, J. 2002. Latent class cluster analysis. In: HAGENAARS, J. \& MCCUTCHEON, A. (eds.) Applied latent class analysis. Cambridge:: Cambridge University Press.

VOYER, M., GLADSTONE, W. \& GOODALL, H. 2013a. 'It's part of me'; The social values of NSW beaches and headlands. Report to the NSW Department of Primary Industries.

VOYER, M., GLADSTONE, W. \& GOODALL, H. 2013b. Understanding marine park opposition: the relationship between social impacts, environmental knowledge and motivation to fish. Aquatic Conservation: Marine and Freshwater Ecosystems, n/a-n/a.

WAITT, G. 2008. 'Killing waves': surfing, space and gender. Social \& Cultural Geography, 9, 75-94.

WAITT, G. \& FRAZER, R. 2012. "The vibe" and "the glide": surf ing through the voices of longboarders. Journal of Australian Studies, 36, 327-343.

WAITT, G. \& WARREN, A. 2008. 'Talking Shit over a Brew after a Good Session with your Mates': surfing, space and masculinity. Australian Geographer, 39, 353-365.

WEST, L. D., K. E. STARK, J. J. MURPHY, LYLE, J. M. \& OCHWADA-DOYLE, F. A. 2015. Survey of Recreational Fishing in New South Wales and the ACT, 2013/14. . Wollongong.

WHITE, D. D. 2008. A structural model of leisure constraints negotiation in outdoor recreation. . Leisure Sciences, 30, 342 - 359.

YOUNG, M. A. L., FOALE, S. \& BELLWOOD, D. R. 2016. Why do fishers fish? A cross-cultural examination of the motivations for fishing. Marine Policy, 66, 114-123.

ZORRILLA-PUJANA, J. \& ROSSI, S. 2014. Integrating environmental education in marine protected areas management in Colombia. Ocean and Coastal Management, 93, 67-75. 

Table 1. Catch and non-catch related motivations included in the LCA modelling.

\begin{tabular}{|l|l|}
\hline Question & \multicolumn{1}{l|}{ Motivational domain } \\
\hline Please rate the importance of each of the following in relation to recreational fishing ${ }^{\text {a }}$ \\
\hline For relaxation/to get away from regular routine & Escapism \\
\hline To be outdoors with nature & Escapism \\
\hline For the challenge or to learn new skills & Mastery \\
\hline To be with family and friends & Socialization \\
\hline The chance of catching a large or trophy fish & Mastery \\
\hline Please indicate the extent to which you agree or disagree with each of the following statements \\
\hline When I go fishing, I am not satisfied unless I catch something & Catching 'something' \\
\hline When I go fishing, I am just as happy if I don't catch a fish & Catching 'something' \\
\hline I am happiest when I catch my bag limit & Catching large numbers of fish \\
\hline The bigger the fish I catch, the better the fishing trip & Catching large sized fish \\
\hline I usually eat the fish I catch & Releasing caught fish \\
\hline I am just as happy if I release the fish I catch & Releasing caught fish \\
\hline
\end{tabular}

${ }^{\mathrm{a}}$ Items from Schramm et al. (2004)

b Items from the Consumptive Orientation Questionnaire (Fisher et al., 1997; Graefe, 1980). 
Table 2. Areas of significant differences $(p<0.05)$ in demographics between internet and phone surveys

\begin{tabular}{|c|c|c|c|}
\hline & $\begin{array}{l}\text { Internet Sample } \\
\quad(n=813)\end{array}$ & $\begin{array}{l}\text { Phone Sample } \\
\quad(n=623)\end{array}$ & p value \\
\hline Age & $45.77(14.22)$ & $50.72(16.70)$ & $<.001$ \\
\hline Sex & & & $<.001$ \\
\hline Male & 744 (92.3\%) & 533 (85.6\%) & \\
\hline Female & $62(7.7 \%)$ & $90(14.4 \%)$ & \\
\hline Country of Birth & & & .043 \\
\hline Australia & 640 (79.4\%) & $521(83.6 \%)$ & \\
\hline Other Country & $166(20.6 \%)$ & 102 (16.4\%) & \\
\hline Marital Status & & & .587 \\
\hline Single & $166(20.4 \%)$ & 120 (19.3\%) & \\
\hline Partnered & 647 (79.6\%) & 503 (80.7\%) & \\
\hline Centrality-to-Lifestyle & $2.79(.84)$ & $2.46(.74)$ & $<.001$ \\
\hline Fishing Frequency ${ }^{a}$ & 44.52 (60.99) & $24.88(33.45)$ & $<.001$ \\
\hline
\end{tabular}


Table 3. Model fit statistics for the LCA models.

\begin{tabular}{cccccc}
\hline & AIC & BIC & Adjusted BIC & BLRT & entropy \\
\hline 1 & 27904.31 & 28020.21 & 27950.32 & & \\
2 & 27237.32 & 27474.39 & 27331.44 & $<.001$ & .67 \\
3 & 26917.30 & 27275.54 & 27059.53 & $<.001$ & .68 \\
4 & 26717.63 & 27197.04 & 26907.96 & $<.001$ & .75 \\
5 & 26550.70 & 27151.27 & 26789.13 & $<.001$ & .76 \\
6 & 26462.95 & 27185.69 & 26750.49 & $<.001$ & .75
\end{tabular}

AIC, Akaike information criteria; BIC, Bayesian information criterion; BLRT, Bootstrap likelihood ratio test. 
Table 4. Motivational priorities for each LCA class.

\begin{tabular}{|c|c|c|c|c|c|c|c|c|c|c|}
\hline & \multicolumn{2}{|c|}{ Social fishers (21.7\%) } & \multicolumn{2}{|c|}{ Trophy fishers (12.5\%) } & \multicolumn{2}{|c|}{$\begin{array}{l}\text { Outdoor Enthusiasts } \\
(28.9 \%)\end{array}$} & \multicolumn{2}{|c|}{ Generalists (14.4\%) } & \multicolumn{2}{|c|}{$\begin{array}{c}\text { Hunter Gatherers } \\
(22.6)\end{array}$} \\
\hline & Neutral & Important & Neutral & Important & Neutral & Important & Neutral & Important & Neutral & Important \\
\hline $\begin{array}{l}\text { For relaxation/get away } \\
\text { from routine }\end{array}$ & 17.3 & 82.7 & 18.2 & 78.1 & 3.7 & 96.0 & 24.4 & 75.3 & 49.5 & 41.0 \\
\hline To be outdoors & 14.8 & 85.2 & 14.4 & 82.0 & 3.7 & 95.1 & 22.1 & 76.4 & 32.0 & 55.0 \\
\hline $\begin{array}{l}\text { For the challenge/ learn } \\
\text { new skills }\end{array}$ & 37.0 & 53.0 & 23.8 & 72.6 & 33.2 & 53.6 & 45.0 & 32.3 & 54.0 & 0.6 \\
\hline $\begin{array}{l}\text { To be with } \\
\text { family/friends }\end{array}$ & 9.0 & 90.6 & 46.3 & 36.9 & 36.3 & 48.4 & 17.0 & 77.8 & 43.3 & 25.5 \\
\hline $\begin{array}{l}\text { For the experience of } \\
\text { catching a fish }\end{array}$ & 29.1 & 70.9 & 18.7 & 81.3 & 36.6 & 48.1 & 59.7 & 19.0 & 58.8 & 18.1 \\
\hline $\begin{array}{l}\text { Not satisfied unless I } \\
\text { catch something }\end{array}$ & 35.0 & 28.9 & 32.9 & 49.3 & 13.0 & 0.6 & 6.3 & 2.4 & 32.7 & 23.6 \\
\hline $\begin{array}{l}\text { Just as happy if I don't } \\
\text { catch a fish }\end{array}$ & 14.9 & 62.2 & 29.3 & 12.5 & 16.9 & 76.5 & 4.4 & 91.7 & 33 & 27.5 \\
\hline $\begin{array}{l}\text { I am happiest when I } \\
\text { catch my bag limit }\end{array}$ & 25.9 & 70.3 & 19.6 & 8.6 & 10.1 & 0.0 & 18.1 & 17.0 & 28.2 & 19.7 \\
\hline $\begin{array}{l}\text { The bigger the fish, the } \\
\text { better the fishing trip }\end{array}$ & 21.2 & 70.4 & 25.4 & 59.0 & 26.6 & 19.3 & 14.0 & 32.8 & 22.6 & 37.2 \\
\hline $\begin{array}{l}\text { I usually eat the fish I } \\
\text { catch }\end{array}$ & 7.9 & 84.3 & 14.7 & 57.1 & 16.4 & 53.3 & 13.0 & 61.9 & 4.0 & 79.1 \\
\hline $\begin{array}{l}\text { Just as happy if I release } \\
\text { the fish I catch }\end{array}$ & 9.8 & 80.5 & 18.5 & 68.1 & 9.1 & 86.9 & 2.1 & 96.6 & 28.0 & 49.6 \\
\hline
\end{tabular}


Table 5. A comparison between the demographic profiles of the identified fisher classes (nb. Values are means, with standard deviation in parenthesis).

\begin{tabular}{|c|c|c|c|c|c|c|}
\hline & Social & $\begin{array}{l}\text { Trophy } \\
\text { fishers }\end{array}$ & $\begin{array}{l}\text { Outdoor } \\
\text { enthusiasts }\end{array}$ & Generalists & $\begin{array}{l}\text { Hunter } \\
\text { Gatherers }\end{array}$ & \\
\hline Sample & & & & & & $<.001$ \\
\hline Internet & 0.6 & 90.4 & 99.8 & 6.4 & 67.3 & \\
\hline Phone & 99.4 & 9.6 & 0.2 & 93.6 & 32.7 & \\
\hline Gender & & & & & & $<.001$ \\
\hline Male & 89.0 & 92.7 & 90.7 & 80.4 & 91.9 & \\
\hline Female & 11.0 & 8.3 & 9.3 & 19.6 & 8.1 & \\
\hline Country of Birth & & & & & & $<.001$ \\
\hline Australia & 86.1 & 79.7 & 72.7 & 84.8 & 86.0 & \\
\hline $\begin{array}{l}\text { Other } \\
\text { country }\end{array}$ & 13.9 & 20.3 & 27.3 & 15.2 & 14.0 & \\
\hline Age & $46.8(17.5)$ & 35.4 (13.9) & $48.1(12.7)$ & $56.0(14.9)$ & $50.6(13.9)$ & $<.001$ \\
\hline $\begin{array}{l}\text { Fishing } \\
\text { frequency } \\
\text { (days/year) }^{\mathrm{a}}\end{array}$ & $26.1(28.9)$ & $44.6(52.3)$ & 40.5 (64.9) & $25.5(40.7)$ & $42.1(54.7)$ & $<.001$ \\
\hline Centrality & $2.67(.75)$ & $2.83(.77)$ & $2.72(.84)$ & $2.27(.72)$ & $2.67(.86)$ & $<.001$ \\
\hline
\end{tabular}

${ }^{\mathrm{a}}$ The high SDs for fishing frequency reflect the skewed distribution for these count data. As a result, comparisons between the classes in relation to fishing frequency were examined using a poisson loglinear regression model. 
Table 6. Focus group participation per profile

\begin{tabular}{|l|l|l|l|l|l|l|l|l|}
\hline Sub group & $\begin{array}{l}\text { FG1 } \\
\text { (Woll) }\end{array}$ & $\begin{array}{l}\text { FG2 } \\
\text { (Woll) }\end{array}$ & $\begin{array}{l}\text { FG3 } \\
\text { (Syd) }\end{array}$ & $\begin{array}{l}\text { FG4 } \\
\text { (Syd) }\end{array}$ & $\begin{array}{l}\text { FG5 } \\
\text { (Syd) }\end{array}$ & $\begin{array}{l}\text { FG6 } \\
\text { (Syd) }\end{array}$ & Total & \% \\
\hline Social & 1 & 1 & 1 & 2 & 1 & 1 & 7 & 21 \\
\hline Trophy fisher & 1 & & & 1 & & & 2 & 6 \\
\hline Outdoor enthusiast & 2 & 1 & & & 1 & 2 & 6 & 18 \\
\hline Generalist & 4 & 1 & 1 & 2 & 6 & 1 & 15 & 44 \\
\hline Hunter gatherers & & & 2 & & & & 2 & 6 \\
\hline Unassigned & 1 & & 1 & & & & 2 & 6 \\
\hline Total & $\mathbf{9}$ & $\mathbf{3}$ & $\mathbf{5}$ & $\mathbf{5}$ & $\mathbf{8}$ & $\mathbf{4}$ & $\mathbf{3 4}$ & $\mathbf{1 0 0}$ \\
\hline
\end{tabular}


Table 7. Fisher classification summary - Recreational fishing profiles and their characteristics from the results of the LCA and focus group discussions.

\begin{tabular}{|c|c|c|c|c|}
\hline Profile & Size & LCA results & Focus group results & Illustrative quote \\
\hline $\begin{array}{l}\text { Social } \\
\text { Fishers. }\end{array}$ & $\begin{array}{l}n=309 \\
21.7 \%\end{array}$ & $\begin{array}{l}\text { Motivated by non-catch-related aspects of fishing, particularly } \\
\text { socialization and escapism. Approximately three-quarters of } \\
\text { individuals indicated that they fished for relaxation and to be } \\
\text { outdoors with nature, while } 85 \% \text { indicated that they fished to be } \\
\text { with friends and family. Catch-specific aspects of fishing were } \\
\text { rated comparatively lower. } 71 \% \text { of individuals indicated that they } \\
\text { are "just as happy if I don't catch a fish" and } 92 \% \text { indicated that } \\
\text { they "just as happy if I release the fish I catch". }\end{array}$ & $\begin{array}{l}\text { Discussion focused primarily on the social and escapism } \\
\text { aspects of fishing, especially on opportunities to } \\
\text { connect with nature, relax and to learn and teach } \\
\text { fishing skills. Decisions about keeping fish often focused } \\
\text { on the idea of catching enough to share with family and } \\
\text { friends. Preferences around size of fish was highly } \\
\text { species specific, often relating to the desirability of the } \\
\text { species for eating. }\end{array}$ & $\begin{array}{l}\text { We'll keep them live in a big tank but if } \\
\text { we don't catch many then I'll say let's } \\
\text { put them back because there's no } \\
\text { point. If we're not going to feed the } \\
\text { whole family then forget it. Social } \\
\text { Fisher - FG5 }\end{array}$ \\
\hline $\begin{array}{l}\text { Trophy } \\
\text { Fishers. }\end{array}$ & $\begin{array}{l}n=177 \\
12.5 \%\end{array}$ & $\begin{array}{l}\text { Motivated primarily by challenge and mastery aspects of fishing, } \\
\text { including catching large fish. } 96 \% \text { indicated they were motivated } \\
\text { by the challenge of fishing and the opportunity to learn new } \\
\text { skills. In addition, } 80 \% \text { indicated that they were motivated to } \\
\text { "catch a trophy fish" and } 80 \% \text { agreed with the statement that } \\
\text { "the bigger the fish I catch, the better the fishing experience". }\end{array}$ & $\begin{array}{l}\text { Under-represented in the focus group sample but } \\
\text { showed clearly distinct preferences in relation to the } \\
\text { other groups. Their discussions around motivation } \\
\text { concentrated almost exclusively on solitary or remote, } \\
\text { catch and release fishing for large fish and chasing } \\
\text { personal milestones or personal bests. }\end{array}$ & $\begin{array}{l}\text { It's purely... for catching the fish, the } \\
\text { fight of the fish and yeah obviously at } \\
\text { the top our mind, is the personal best I } \\
\text { guess... it's the size of the fish that's } \\
\text { most important. Trophy Fisher - FG3 }\end{array}$ \\
\hline $\begin{array}{l}\text { Outdoor } \\
\text { Enthusiasts }\end{array}$ & $\begin{array}{l}n=410 \\
28.9 \%\end{array}$ & $\begin{array}{l}\text { Tend to fish primarily for the opportunity for escapism and being } \\
\text { outdoors. Approximately } 95 \% \text { of individuals indicated that } \\
\text { relaxation and being outdoors with nature were important } \\
\text { aspects of fishing. Catch-related aspects of fishing such as } \\
\text { catching fish, catching trophy fish, and catching large numbers of } \\
\text { fish were not considered important. Furthermore, challenge and } \\
\text { socialization aspects of fishing were rated lowly. }\end{array}$ & $\begin{array}{l}\text { Placed far less emphasis on catching something and } \\
\text { were much more motivated by a desire to connect with } \\
\text { nature, relax and 'de-stress'. This frequently involved } \\
\text { fishing on their own or in remote locations. The } \\
\text { challenge aspect of fishing for this group had particular } \\
\text { relationships with their nature based preferences, and } \\
\text { often involving building skills and knowledge to trick or } \\
\text { outsmart the fish or working with or against natural } \\
\text { conditions to land a fish. }\end{array}$ & $\begin{array}{l}\text { I always fish primarily by myself; it's the } \\
\text { challenge of looking at the conditions, } \\
\text { working out what's my best chance, } \\
\text { where I should go, what lure I should } \\
\text { use... and just the satisfaction of } \\
\text { actually getting the fish. Outdoor } \\
\text { enthusiast - FG1 }\end{array}$ \\
\hline Generalists & $\begin{array}{l}n=205 \\
14.4 \%\end{array}$ & $\begin{array}{l}\text { A mix of fishing motivations. Individuals in this class rated } \\
\text { escapism as an important aspect of fishing. The majority } \\
\text { disagreed that catching fish, catching large fish, and catching } \\
\text { large numbers of fish were important, and } 85 \% \text { indicated they } \\
\text { would be just as happy if they released the fish they caught. }\end{array}$ & $\begin{array}{l}\text { A mix of motivations, with greater emphasis on } \\
\text { escapism and socialization aspects of fishing over } \\
\text { mastery. Like social fishers the size of the fish pursued } \\
\text { was largely species and context specific and relating } \\
\text { mostly to 'keeping what I need' and releasing the rest. }\end{array}$ & $\begin{array}{l}\text { The relaxing part of it is a big motivator } \\
\text { especially with the stresses of work... If } \\
\text { the tide is right the anticipation of } \\
\text { nailing a couple of big fish is pretty } \\
\text { cool. That can be with friends or on my } \\
\text { own. Generalist- FG1 }\end{array}$ \\
\hline $\begin{array}{l}\text { Hunter } \\
\text { Gatherers }\end{array}$ & $\begin{array}{l}n=321 \\
22.6 \%\end{array}$ & $\begin{array}{l}\text { A mix of different motivations, and a comparatively large } \\
\text { percentage of individuals who gave neutral responses to each } \\
\text { item. However, } 80 \% \text { of respondents usually ate the fish they } \\
\text { caught and only } 44 \% \text { indicated that they would be just as happy } \\
\text { if they released the fish they caught. This suggests that } \\
\text { consumption of fish is the most important characteristic of this } \\
\text { class. }\end{array}$ & $\begin{array}{l}\text { Greater discussion of keeping fish, centering on a desire } \\
\text { to catch sufficient fish for a meal. A preference to keep } \\
\text { the catch. Less inclined to fish for the purposes of catch } \\
\text { and release. Discussion of challenge/mastery tended to } \\
\text { focus on an enjoyment of the 'gamble' of fishing or a } \\
\text { belief that their catches were more about luck than skill. }\end{array}$ & $\begin{array}{l}\text { I'm part of a fishing club and there are } \\
\text { a lot of guys in that that I think are } \\
\text { artists, whereas I'd probably use } \\
\text { dynamite if I was allowed....I'm } \\
\text { certainly more of a skull dragger than a } \\
\text { finesse fisherperson. Hunter Gatherer- } \\
\text { FG3 }\end{array}$ \\
\hline
\end{tabular}


Table 8. Presence or absence of 'mastery' motivation in focus group participants

\begin{tabular}{|l|l|l|l|}
\hline \multirow{2}{*}{ Fisher Class } & \multicolumn{2}{|c|}{ Mastery } & \multirow{2}{*}{ Total } \\
\cline { 2 - 3 } & Yes & No & \\
\hline Social & 3 & 4 & 7 \\
\hline Trophy & 2 & 0 & 2 \\
\hline Outdoor & 5 & 1 & 6 \\
\hline Generalist & 9 & 6 & 15 \\
\hline Hunter & 2 & 0 & 2 \\
\hline Unassigned & 0 & 2 & 2 \\
\hline Total & $\mathbf{2 1}$ & $\mathbf{1 3}$ & $\mathbf{3 4}$ \\
\hline
\end{tabular}


Table 9. Intersection of 'mastery' motivation with attitudinal themes amongst focus group participants

\begin{tabular}{|c|c|c|}
\hline \multirow[t]{2}{*}{ Topic area } & \multicolumn{2}{|c|}{ Dominant themes } \\
\hline & $\begin{array}{l}\text { Fisher for whom mastery motivations were } \\
\text { important }\end{array}$ & $\begin{array}{l}\text { Fishers for whom mastery motivations } \\
\text { were not important }\end{array}$ \\
\hline $\begin{array}{l}\text { Commercial } \\
\text { fishing }\end{array}$ & $\begin{array}{l}41 \% \text { indicated concerns about commercial fishing } \\
\text { management in NSW, largely framed as belief } \\
\text { that they take all the fish. } 45 \% \text { indicated that } \\
\text { commercial fishing should be reduced in favor of } \\
\text { greater recreational fishing. } 32 \% \text { felt that } \\
\text { recreationally fishing was more sustainable and } \\
\text { worth more to the community than commercial } \\
\text { fishing. } 18 \% \text { indicated that they believed } \\
\text { commercial fishers were unfairly favored over } \\
\text { recreational fishers. } \\
\text { You can ask anyone that goes out fishing, they'll tell } \\
\text { you that once they've been through there's nothing left } \\
\text { for quite a few weeks... We have size limits imposed on } \\
\text { us and then you can walk past the fish shop...you'll see } \\
\text { small fish that a recreational fisher is not allowed to } \\
\text { keep but... commercial fisherman keep them and } \\
\text { they're on sale. Outdoor enthusiast FG2 }\end{array}$ & $\begin{array}{l}50 \% \text { discussed commercial fishing by } \\
\text { focusing on global overfishing, } \\
\text { international fishing practices or factory } \\
\text { ships. Only } 17 \% \text { discussed concerns about } \\
\text { commercial fishing management in NSW. } \\
\text { Well I mean, you've only got to watch the so- } \\
\text { called reality shows they show on TV...they're } \\
\text { throwing away everything they pull out of the } \\
\text { water because they've dredged so deep for the } \\
\text { crabs they want, the stuff they bring to the } \\
\text { surface, dies. Social fisher FG4 }\end{array}$ \\
\hline $\begin{array}{l}\text { Marine } \\
\text { Protected } \\
\text { Areas }\end{array}$ & $\begin{array}{l}\text { 36\% indicated that they believed the impacts of } \\
\text { MPAs outweigh effectiveness, largely relating to } \\
\text { concerns over being 'locked out' for 'no good } \\
\text { reason'. } \\
\text { The fishermen are forced to fish in the barren areas } \\
\text { and all the fish are in the marine parks... I'm basically } \\
\text { a conservationist but I hate the prospect of being told } \\
\text { this is a place where you can't fish. Social fisher FG6 } \\
23 \% \text { indicated that they were not concerned by } \\
\text { MPAs as they had no impact on their activities. }\end{array}$ & $\begin{array}{l}42 \% \text { indicated that they felt stress and or } \\
\text { confusion about MPAs, especially in } \\
\text { relation to zoning boundaries. } 42 \% \\
\text { indicated support for the concept of MPAs } \\
\text { but a lack of trust in the process for } \\
\text { declaring MPAs. } \\
\text { The first word that pops into my mind is } \\
\text { confusion... Where am I allowed to go and } \\
\text { where am I not allowed to go? You know, } \\
\text { you've got to make it easy to understand - I'm } \\
\text { not a dimwit, I don't think. But I find it hard. } \\
\text { Generalist fisher FG4 }\end{array}$ \\
\hline $\begin{array}{l}\text { Recreational } \\
\text { fisheries } \\
\text { management }\end{array}$ & $\begin{array}{l}32 \% \text { supported current management } \\
\text { arrangements. } 27 \% \text { supported tightening } \\
\text { recreational catch and/or size limits. }\end{array}$ & $\begin{array}{l}50 \% \text { were concern over fishing practices of } \\
\text { some ethnic groups within the } \\
\text { community. }\end{array}$ \\
\hline
\end{tabular}


Figure 1. Characteristics of the five identified latent classes.

1 =relaxation/get away from routine; $2=$ Outdoors with nature; $3=$ Challenge/ learn new skills; $4=\mathrm{Be}$ with family and friends; $5=$ Catch trophy fish; $6=$ not satisfied unless something caught; $7=$ Happy if I don't catch a fish; 8 =Happiest when I catch my bag limit; $9=$ Catching big fish is a good trip; $10=$ Eat caught fish; 11= Happy to release caught fish.

Figure 1A. Social Fishers

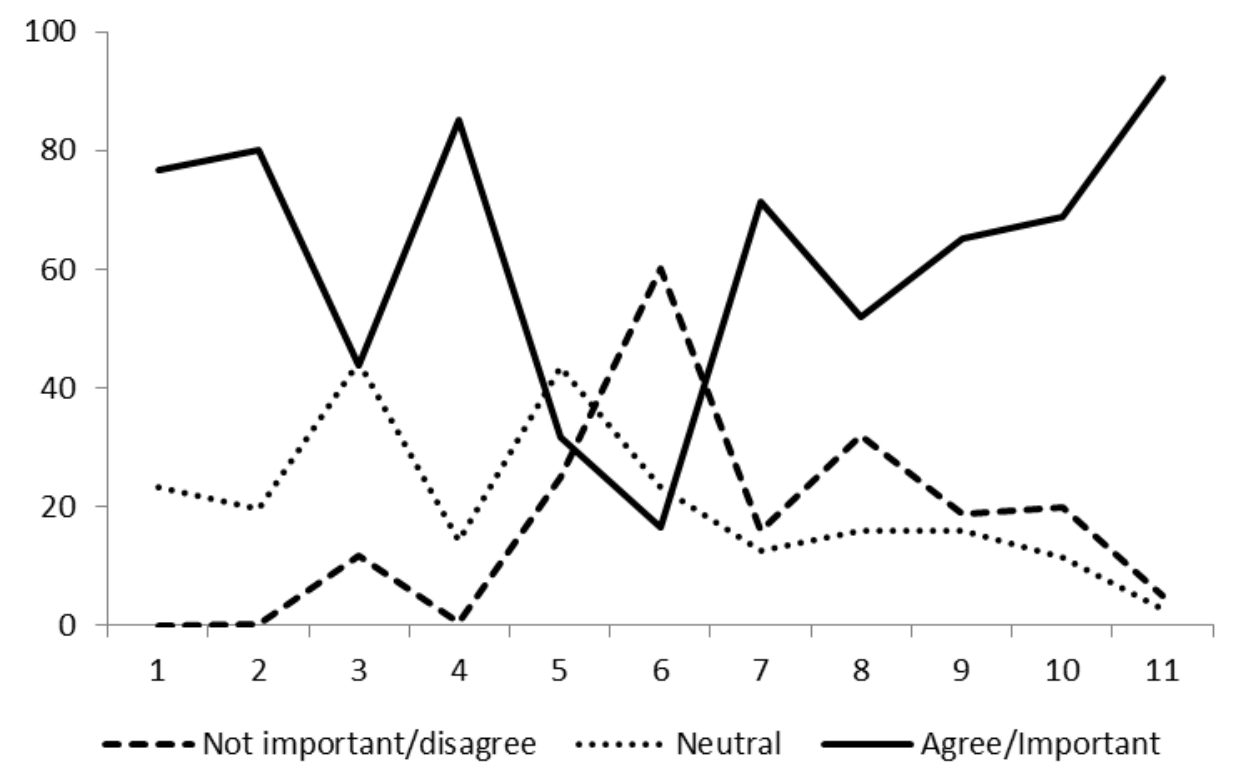


Figure 1B. Trophy fishers

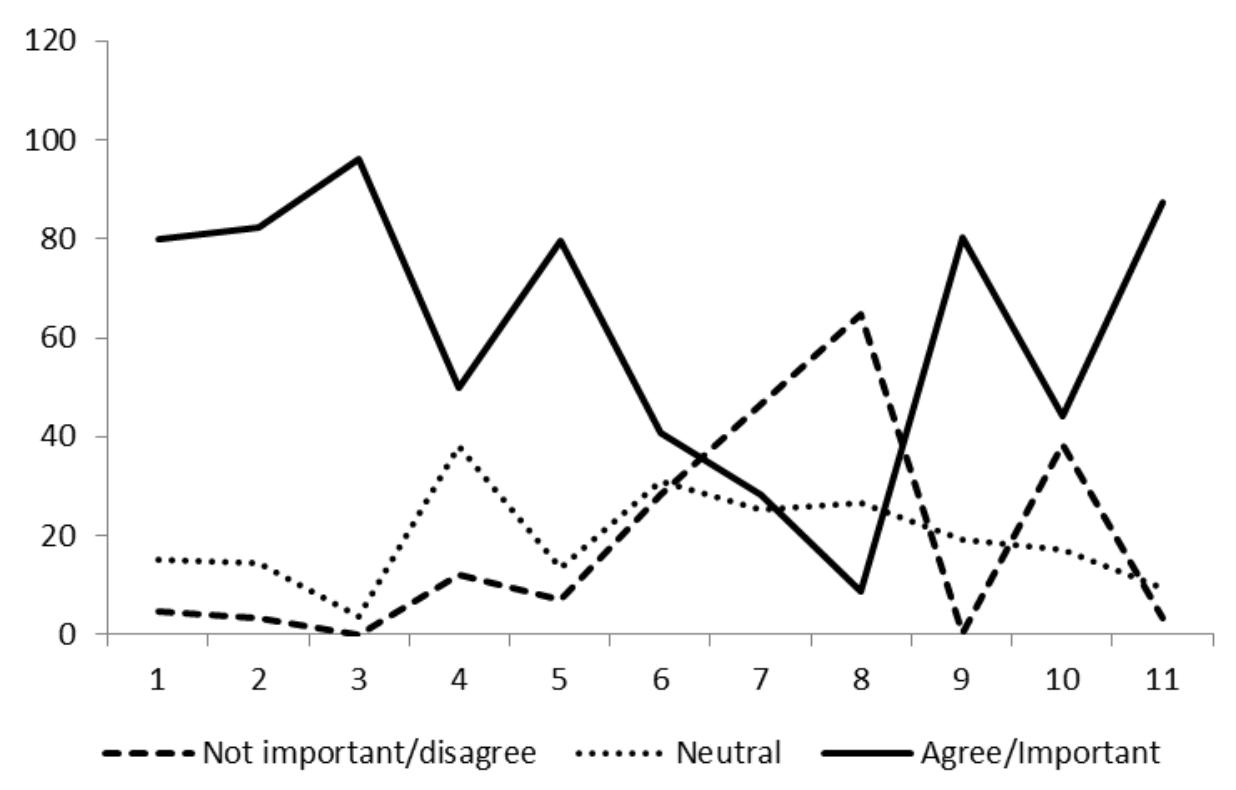


Figure 1C. Outdoor Enthusiasts

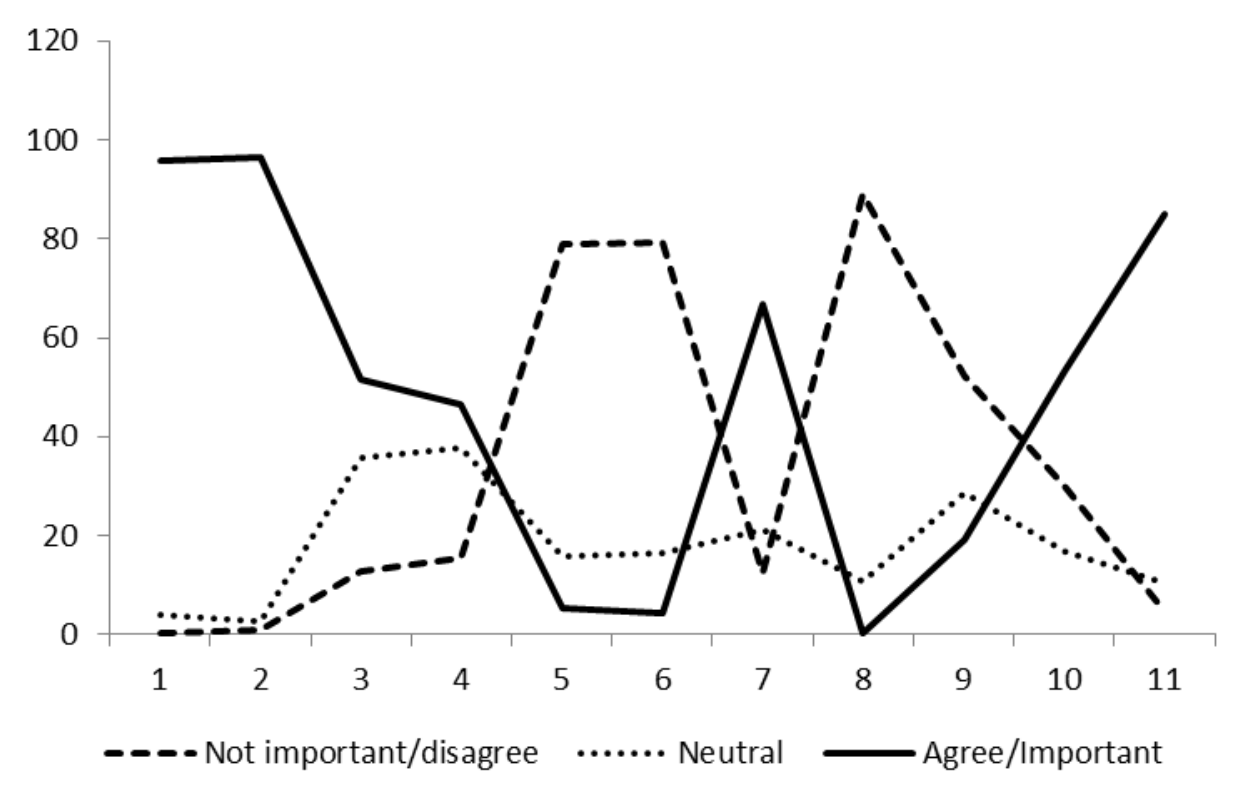


Figure 1D. Generalists

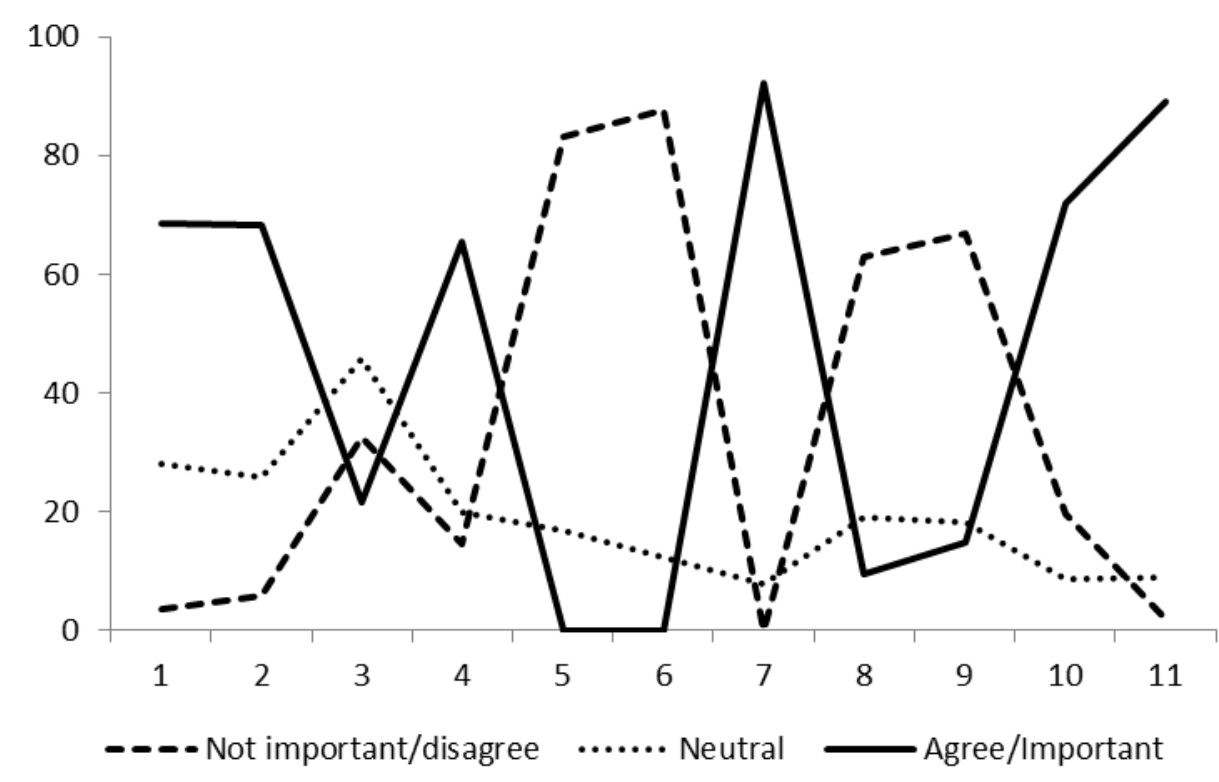


Figure 1E. Hunter Gatherers.

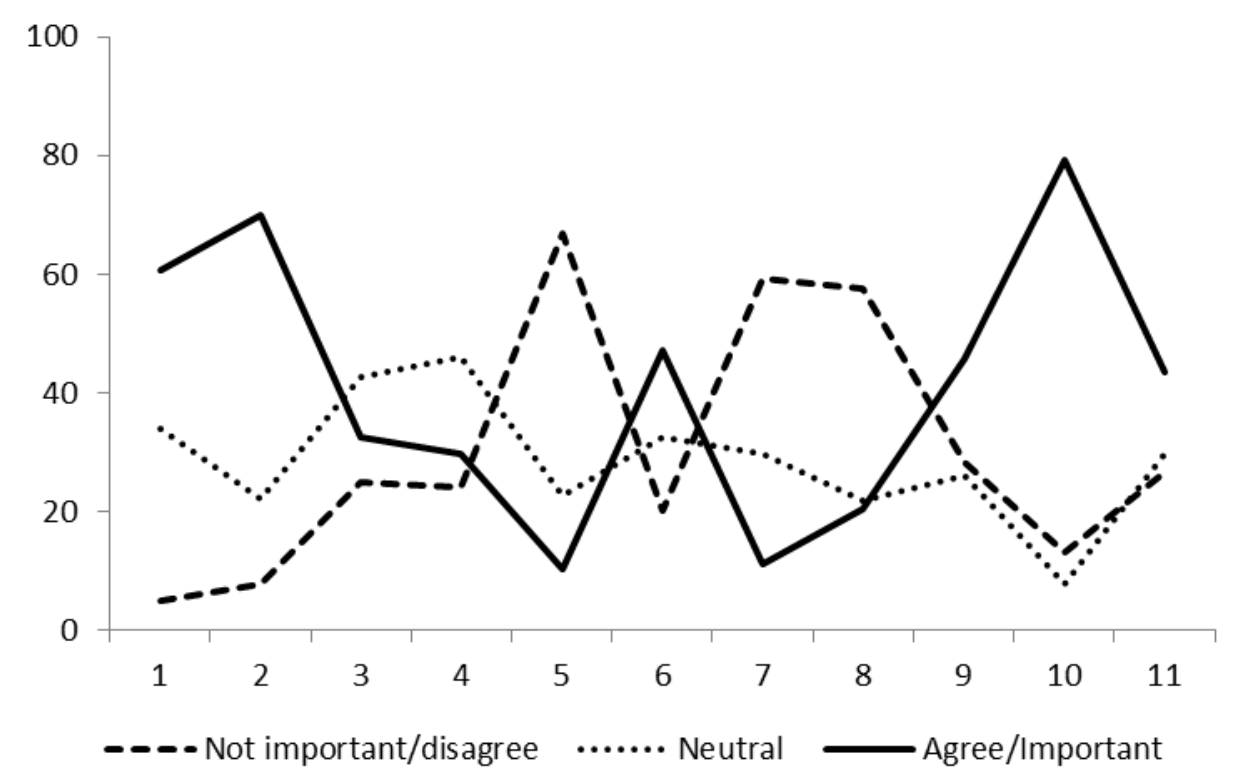


Figure 2

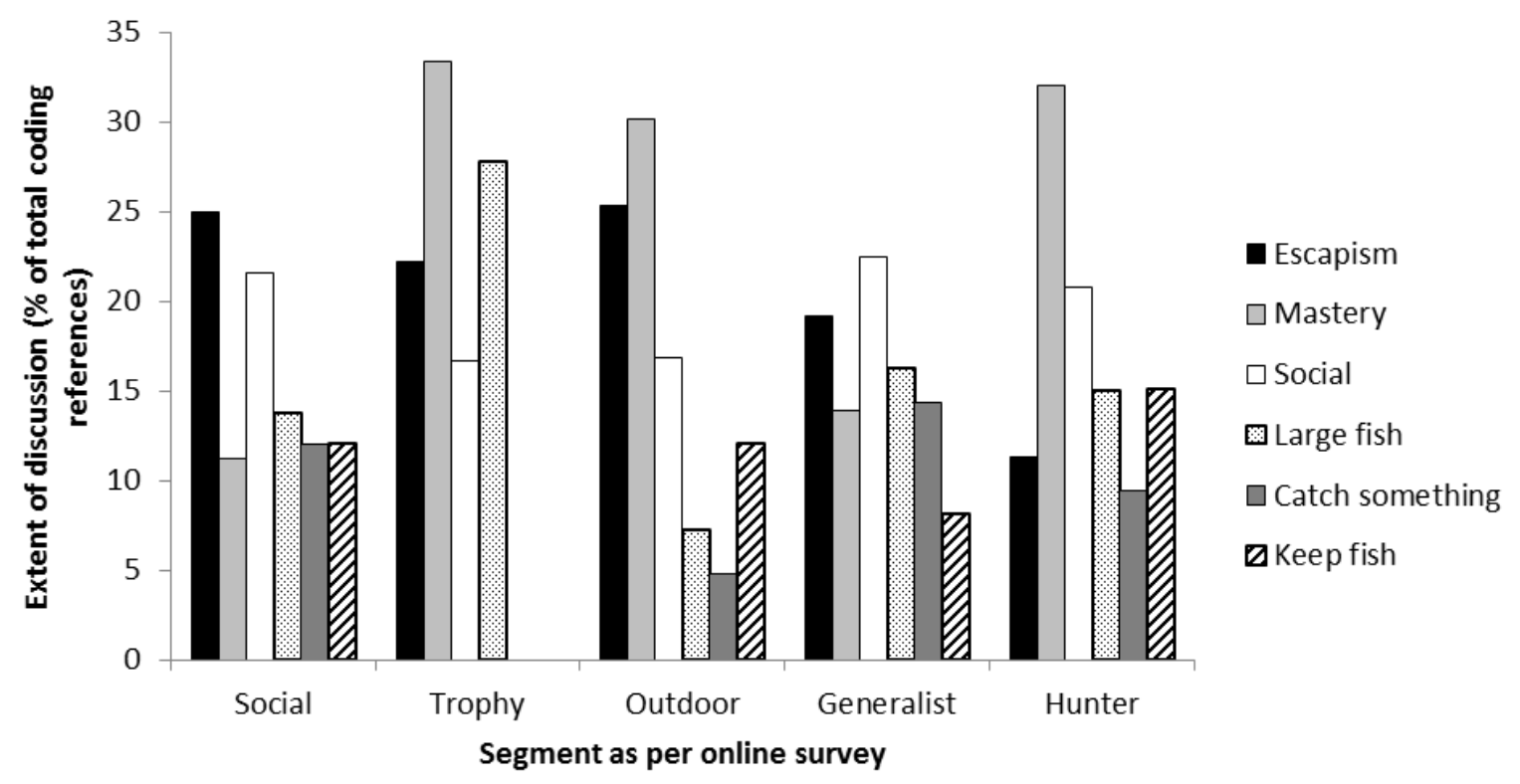

